\title{
Nano Ag@Bioactive Microspheres From Marine Sponge Clathria Frondifera. Fabrication, Fortification, Characterization and Antibacterial Potential Evaluation
}

\section{K. Saravanakumar}

V. H. N. Senthikumara Nadar College (Autonomous)

\section{Abinaya}

V. H. N. Senthikumara Nadar College (Autonomous)

\section{S. Mehnath}

University of Madras

\section{Jeyaraj}

University of Madras

V. Muthuraj ( $\square$ muthuraj75@gmail.com )

V. H. N. Senthikumara Nadar College (Autonomous) https://orcid.org/0000-0002-4702-4136

\section{Research Article}

Keywords: Marine sponge, Clathria frondifera, silver fortification, antimicrobial efficacy, anticancer activity.

Posted Date: July 29th, 2021

DOl: https://doi.org/10.21203/rs.3.rs-750604/v1

License: (c) (i) This work is licensed under a Creative Commons Attribution 4.0 International License. Read Full License

Version of Record: A version of this preprint was published at Environmental Research on October 1st, 2021. See the published version at https://doi.org/10.1016/j.envres.2021.112282. 


\section{Abstract}

Bioresources are attaining much importance in the discovery of drugs and delivering agents. In particular, marine sponges are of great interest due to their metabolites production for the survival in risky environment. The incorporation of silver nanoparticles with marine sponge derived metabolites was reported for the first time. In this work, a facile material has been generated of great efficacy in solving environmental and health issues, as a recipe of silver and marine sponge Clathria frondifera, named as Ag Fortified Sponge spheres (AFS). AFS spheres were successfully synthesized after method optimization, using the various extracts of marine sponge Clathria frondifera as effective reducing agent in $\mathrm{Ag}(\mathrm{I})$ to $\mathrm{Ag}(0)$ reduction. Bioactive material from marine sponge and AgNP from the reduction of $\mathrm{AgNO}_{3}$ solution stablishing one another and thus AFS spheres were attaining long lifetime along with enhanced antimicrobial activity. The characterization of synthesized AFS and other AgNPs (1-4) has done using FT-IR, PXRD, FESEM, TEM, UV-vis and PL data. The cytotoxic response of AFS was assessed by 3(4, 5-dimethylthiazol-2-yl)-2, 5-diphenyltetrazolium bromide (MTT) and morphological changes. AFS are exact spherical, micro sized and effective in inhibiting the growth of both gram positive and gram negative bacteria. Anticancer studies were also carried out and ensued with excellent activity in the HELA cells.

\section{Highlights}

- A novel material has been synthesized by incorporating the two materials of different stream.

- Simple, cost- effective and eco-friendly procedure for the synthesis of a bio nano combinatorial materials as Ag fortified marine sponge spheres

- Biomaterials derived from the marine sponge Clathria frondifera and the in-situ stabilized silver nanoparticles using various solvents.

- The sponge biomaterial enriches the antimicrobial and anticancer activity

- At the same time silver fortification enhances the stability of the material.

\section{Introduction}

More than $70 \%$ of earth surface was made up of water. Many living organisms are surviving in this water sources, totally known as marine environment. The marine world organisms provide more bioactive materials which are having many medicinal properties. Usually most of the marine organisms produce primary and secondary metabolites to survive in the challenging circumstances ${ }^{1}$. Metabolic profiling of various marine species brings an excellent source for pharmaceuticals. Drug development based on marine-derived metabolites was rapidly stepping into the drug candidature list due to their far-fetched properties found in lot of marine animals. Marine sponges (phylum Porifera) are having higher ability to produce numerous unique metabolites to protect and survive in the challenging environment. Sponges were of three classes namely Calcaarea, Demospongiae and Hexactinellida and among them three genera classified as great bioactive sources (Haliclona, Petrosia and Discodemia) ${ }^{2,3}$. Currently there are 
more than 15000 identified sponge species, 5000 isolated compounds, which covers around $30 \%$ of the total discovered marine natural products ${ }^{4}$. Thus sponges were of great interest and an important source of pharmaceuticals in treating many diseases. The secondary metabolites produced by marine sponges were of different chemical structures and includes unique medicinal properties. Particularly, marine sponges of clathria family were delivering many metabolites of various structural forms such as steroids, alkaloids, terpenoids, sugars, lipids, peptides, nucleosides and carotinoids ${ }^{5,6}$. Researchers were using the bioextracts of marine sponge for the biosynthesis of various nanocompounds, likely from plant extracts and marine algae.

D. Inbakandan et.a/ reported the biosynthesis of silver and gold nanoparticles using extract of marine sponge Acanthella elongate ${ }^{7}$. M. R. Hamedet.a/ reported the biosynthesis of silver nanoparticles from aqueous extract of marine sponge Haliclona ${ }^{8}$ and Axinella sinoxia ${ }^{9}$. Y. N. Shkryl et al reported the green synthesis of silver nanoparticles using transgenic Nicotianatabacum callus culture expressing silicatein gene from marine sponge Latrunculia oparina ${ }^{10}$. Marine sponge Clathria frondifera is the species found in Indian ocean specifically in mandapam sea area, which is not yet studied. G. Radhika et al isolated clinically important N-Methylpyrrolidone from marine sponge Clathria frondifera ${ }^{11}$ and our research group has reported the antimicrobial potential of the mixture of compounds separated from marine sponge Clathria frondifera ${ }^{12}$.

For the past few years, cancer is the majestic killer disease causing fear among human being ${ }^{13}$. Very few of the cancer patients surviving a little longer or attaining cure through some processes such as major surgical treatments, removal or transplantation organs, blood transaction, photodynamic therapy, chemotherapy and also with immune checkpoint inhibitors ${ }^{14-17}$. But still there is a huge need for cancer medications which are much effective than currently available drugs. In order to bring that much effective medicine for tumours, researchers are producing many combinatorial drug candidates for treating cancer. On that basis, bioresources coupled with nanomedicine could perform much and there are no much reports yet in this combination. In nanomedicine, noble metals such as silver nanoparticles, colloidal gold, were doing a handsome of performance in treating cancer ${ }^{18-21}$.

Silver nanoparticles are the great hope for those in anticancer drug discovery, which is one of wide spread applications of silver $^{22}$. Silver nanoparticles have received major attention due to their unique and tuneable Surface Plasmon resonance (SPR) ${ }^{23}$ and their well-known antimicrobial activity ${ }^{24}$ from ancient medicine to till now. Existing strategies for the green synthesis of silver nanoparticles (Ag NPs) are not well established and fabrication of size and shape controlled Ag NPs also includes some tedious time taking processes such as decanting, centrifuging, aging along with maintenance of constant $\mathrm{pH}$, temperature, pressure, light irradiation and so on ${ }^{25-29}$. Under these conditions, the introduction of several elements on the same nanomaterial in a desired ratio and density is particularly difficult to achieve. Silver nanoparticles should be designed with fixed consideration for oriental application to ensure the absence of any crossover side effects. Synthesis of various noble metallic nanoparticles has been carried out using bio extracts with easiest procedures for the reduction of metal ions into elemental metal in nano 
size. Bio-extracts are acting as a source of reduction either extracellularly or internally ${ }^{30}$. Synthesis of silver nanoparticles using ocean based bio extracts such as seaweeds, bacteria, cyanobacteria, yeast, fungi, marine biofilms, marine algae, marine spermatophytes, marine sponges, fish extracts are attaining prodigious attention by researchers due to their mysterious activities in biological systems ${ }^{31-33}$. The mass quantities of unique natural products in underwater resources are detectable in invertebrates like sponges, tunicates, bryozoans ${ }^{34-36}$. The important components were found include amines groups, hydroxyls, phenols, carbonyl and alkyl halides ${ }^{37}$. The emerging development of biosynthesis of nanoparticles using marine organisms is demarcated as hi-tech tactic with eco-friendly approachability. Especially metal nanoparticle synthesis using marine sponge extract is not established much, only very few reports were found worldwide.

To the best of our knowledge and searching in literature, AgNP incorporated marine sponge biometabolites derived materials were uncharted. The synthesis of a material combination of organic extracts from natural products or biological sources with metallic nanoparticles especially silver in a green protocol is a novel area, in which we got interest. The aim of present investigation is to develop a simple, cost- effective and eco-friendly procedure for the synthesis of bio nano combinatorial materials as Ag fortified marine sponge spheres.

\section{Materials And Methods}

\section{Materials}

Silver nitrate $\left(\mathrm{AgNO}_{3}\right)$ and all other chemicals were purchased from the Merck Chemicals, India. All the solvents used for this work were purchased from Finar limited, India. Silica gel (100-120 mesh) was purchased from silvery enterprises Itd., India. Clathria frondifera marine sponge was collected in mandapam sea area, Tamilnadu. The freshly collected marine sponge were washed several times with running tap water and then with double distilled water to remove excess salt from sea water. Deionized water was used for the preparation of all solutions. All the reagents were analytically pure (AR) and use as received without further purification.

\section{Preparation of marine sponge extract}

\section{Extract l:}

$5 \mathrm{~g}$ of the shadow dried marine sponge were weighed and boiled for $15 \mathrm{~min}$ in $100 \mathrm{ml}$ double distilled water and the extracts are filtered through Whatman No.1 filter paper. The pure aqueous extracts were stored in a cool and dark place.

\section{Extract II:}

Another $5 \mathrm{~g}$ of shadow dried marine sponge were crushed manually in mortar and sieved to get uniform mesh. About $1 \mathrm{~g}$ of crushed sponge powder were directly soaked in $100 \mathrm{ml}$ of methanol-deionized water 
mixed solvent of ratio 1:10 for $12 \mathrm{~h}$, stirred for another $12 \mathrm{~h}$ and allowed to stand for $2 \mathrm{~h}$. Then the supernatant was centrifuged, concentrated and stored in separate glass sample container in dark for further use.

\section{Sample preparation for GC-MS}

One portion of the both extracts were completely dried in rotary evaporator to obtain powder extracts and then all ethyl acetate soluble matter were completely separated out using column chromatography. This pure ethyl acetate extracts were concentrated and stored in a clean glass sample container for using GCMS analysis.

\section{Synthesis of Ag nanoparticles (AgNP) 1-4}

$100 \mathrm{~mL}$ of each extract (I \& II) was taken in separate beakers and mixed with $100 \mathrm{~mL}$ of $0.05 \mathrm{M}$ $\mathrm{AgNO}_{3}$ solution in $500 \mathrm{ml}$ Erlenmeyer flask at room temperature. After $30 \mathrm{~min}$ of vigorous mixing, the flasks were kept aside for $24 \mathrm{~h}$ in cool and dark place. Every $2 \mathrm{~h}$, the flask was monitored to check the colour of the solution. In the synthesis using extract $\mathrm{l}$, the light yellow colour solution slowly becomes ruby red colour. In the synthesis using extract II, the solution changed into brownish within $4 \mathrm{~h}$ then there was further noticeable difference in the intensity upto $20 \mathrm{~h}$, after that no change in the appearance of solution, which confirmed that the bio-reduction process is over within $24 \mathrm{~h}$. After $24 \mathrm{~h}$, both the synthesized AgNPs ( 1 \& 3) were collected by centrifugation at $3000 \mathrm{rpm}$ for $20 \mathrm{~min}$ and it was purified with double distilled water for three times. Then the AgNPs were allowed to dry at room temperature.

$10 \mathrm{ml}$ of concentrated extract I was mixed with $30 \mathrm{ml}$ of $0.05 \mathrm{M} \mathrm{AgNO}_{3}$ solution with continuous $500 \mathrm{rpm}$ magnetic stirring at room temperature in a glass beaker. The synthesis of $\mathrm{AgNP}_{3}$ using extract I was completed after $2 \mathrm{~h}$ magnetic stirring. Various stoichiometric ratios (1:1, 1:2, 2:1, 1:3 and 3:1) of 0.05 $\mathrm{M} \mathrm{AgNO}_{3}$ and extract II solutions were taken for the synthesis of AgNP4. After the addition of extract II, within 10s the pale yellow colour changed into blackish brown. Then after 2 min stirring, the synthesized silver nanoparticles (AgNP4) were collected and washed several times with deionized water and dried in vacuum. Finally, all the synthesized silver nanoparticles were stored in a screw capped bottle for further characterization and were labelled as AgNP1-4 as shown in table 1.

\section{Characterization}

FT-IR spectra of dry sponge powder was taken in Fourier Transform Infrared spectrophotometer. The marine sponge Clathria frondifera extracts I and II were analysed using GC-MS. The visual properties of the product were investigated by UV-visible absorption spectrometer at the wavelength range of 200-800 $\mathrm{nm}$ with acetone dispersed samples in quartz cuvette. Powder X-ray diffraction (XRD) spectral data were collected diffractometer. EDAX spectra of as synthesized AgNP and AFS were taken to confirm no more impurity or any other elements present in AgNP (Ag) and AFS (Ag, C, N and O). SEM images were recorded at 40,000x magnifications operating with $20.00 \mathrm{kV}$. TEM images of Ag NPs and AFS were taken Transmission electron microscope. 


\section{Evaluation of antimicrobial activity}

The antibacterial study of Ag nano spheres was performed against the pure cultures of human pathogenic bacteria such as Bacillus subtilis, Escherichia coli, Staphylococcus aureus and Pseudomonas aeruginosa were isolated from clinical sample. It was confirmed by various biochemical tests. These were obtained from Microbiology Department, VHNSN College, Virudhunagar, India. Bacterial strains were cultured overnight at $37^{\circ} \mathrm{C}$ in Muller-Hinton broth for antimicrobial activity tests. Test strains were suspended in nutrient agar to give a final density of 5 X105 CFU/ml. The Minimum Inhibition Concentration (MIC) value was expressed as the lowest concentration inhibiting the bacterial growth. The method was recommended by the National committee for clinical Laboratory Standards (1). Nutrient agar $(20 \mathrm{ml})$ was poured into each sterile Petri plates after inoculating culture $(100 \mu \mathrm{l})$ of microorganisms and distributing medium in Petri plates homogenously. To make three wells on nutrient agar medium were added $25 \mu \mathrm{l}$ and $50 \mu \mathrm{l}$ of AFS sample. The plates were incubated at $37^{\circ} \mathrm{C}$ for $24 \mathrm{~h}$. Inhibition zones formed on the medium were evaluated in $\mathrm{mm}$ and the streptomycin antibiotic was used as the positive control.

\section{In vitro cytotoxicity studies}

HELA cells were cultured in DMEM supplemented with $10 \%$ fetal bovine serum at $37^{\circ} \mathrm{C}$ in a humidified incubator containing $5 \% \mathrm{CO}_{2}$. To check the cytotoxicity by MTT assay, HELA cells were seeded separately in a 96 well plate at a density of $4 \times 10^{3}$ cells per well and were incubated in the media containing marine sponge and AFS at various concentrations $\left(20,40,60,80,100,120\right.$ and $\left.140 \mu \mathrm{g} \cdot \mathrm{mL}^{-1}\right)$ for $24 \mathrm{~h}$. Cytotoxicity was measured by MTT assay and the absorbance was read at $595 \mathrm{~nm}$.

\section{Morphological assessment}

HELA cells were cultured with and without marine sponge and AFS at various concentrations $(80,100$ and $\left.120 \mu \mathrm{g} \cdot \mathrm{mL}^{-1}\right)$. For all untreated and treated HELA cells, the images were viewed at $24 \mathrm{~h}$ and the images were captured usinga phase contrast microscope.

\section{Cellular uptake}

BSA-FITC coated silver nanoparticles were prepared by $1 \mathrm{~mL}$ of the AgNPs mixed with $0.5 \mathrm{~mL}$ BSA-FITC $(0.15 \mu \mathrm{mol})$ and $1 \mathrm{~mL} \mathrm{NaOH}(0.1 \mathrm{M})$. The mixture was stirred for 3days and FITC-AgNPs were separated by dialysis method. HELA cells were grown in a 6-well plate and FITC-AgNPs of 1 to $4 \mu \mathrm{M}$ was added to the cells and visualized under fluorescence microscope.

\section{Results And Discussion}

\subsection{Structural, optical and morphological properties}


The crystalline phase and purity of the as-synthesized AgNP materials were examined by PXRD analysis and combined patterns are shown in Fig.4. for AgNP1 all the diffraction peaks can be indexed to an orthorhombic phase of Ag nano spheres and is good consistence with the standard JCPDS card no. [040783]. There are no other significant impurities were identified which revealed that successful formation pure AgNP1 but small hump in between the angles 10 and 20. This indicates the presence of bioactive materials from marine sponge but not fully intermixed. Then the XRD pattern of AFS shows the presence of organic molecules overlapped with Ag. The four high intense peaks can be attributed to the (111), (200), (220), and (311) planes of AgNP respectively. The average crystallite size was calculated by Scherer's formula ${ }^{12}$ and the size is to be nearly $10-20 \mathrm{~nm}$.

Fig. 3 shows that the complete surface Plasmon resonance (at $450 \mathrm{~nm}$ ) detected in AFs while comparing to AgNPs in UV-Visible spectra of both. Fig.1 represents the FTIR spectrum of AFS and the peaks were observed at 995,871 and $580 \mathrm{~cm}^{-1}$ which can be ascribed to metal nanoparticles. The band observed at 1741 and $1649 \mathrm{~cm}^{-1}$ were related the $\mathrm{C}=\mathrm{O}$ and $-\mathrm{OH}$ bending modes, respectively. The bands at 1514 and $1400 \mathrm{~cm}^{-1}$ were corresponding to the $\mathrm{C}-\mathrm{C}$ aromatic vibrations and $\mathrm{C}-\mathrm{H}$ deformation vibrations. The sharp band at $1153 \mathrm{~cm}^{-1}$ can be attributed to a carbonyl group such as in aldehyde or ketone group.

The surface morphology of the as-synthesized AgNPs 1-4 was observed using Scanning electron microscopy (SEM) analysis and presented in Fig. 5 and 6. The SEM images displayed the sphere-like structure of Ag nanoparticles in both AgNP (Fig. 5) and AFS (Fig 6) with relatively smooth surfaces. The average diameter is $\sim 20 \mathrm{~nm}$ and the diameter of sponge sphere is to be $200 \mathrm{~nm}$. In Fig. 6, All AgNPs synthesised using various stoichiometric ratios of $\mathrm{AgNO}_{3}$ and extract Il solutions were exhibiting same shape but with slight differences in size and Ag particle distributions.

The elemental compositions were investigated by Energy dispersive x-ray studies (EDX) in Fig. 7 which revealed that the presence of $\mathrm{Ag}, \mathrm{C}, \mathrm{N}$ and $\mathrm{O}$ elements in AFS. No other significant elements were identified which proved the presence of bioactive organic compounds which stablishing the silver nanoparticles on its surface. Fig. 8 exhibits the elemental mapping of AgNP4 composite. The red colour image was showing that the spectra of silver which was clearly spread over the sponge microsphere. The green colour image shows the presence of carbon in equivalent quantity with silver. The blue and yellow colour images were acquired for nitrogen and oxygen elements respectively. The presence of the elements carbon, oxygen and nitrogen shows the microsphere is derived from complete organic substances of marine sponge material. Moreover, the transmission electron microscopy with different magnifications in Fig 9 (A \& B) further confirmed the successful formation of sphere-like AgNP2 and successful Ag fortification on sponge sphere and formation as AFS.

\subsection{Anti-Microbial assay}

In this present investigation, we evaluated the anti-microbial activity of as-synthesized AFS with different concentrations, sodium molybdate and stem extracts in various organisms like Bacillus subtilis (B.subtilis), E. coli, Staphylococcusaureus (S.aureus) and Pseudomonas aeruginosa (P.aeruginosa) 
colonies on nutrient agar plates supplemented with AFS and the results are shown in Fig.8. The standard antibiotic drug streptomycin was used as a positive control. The zone of inhibitions with different concentrations of AFS and marine sponge powder extract was carried out and the results are shown in Fig. 5 and were tabulated in fig. 8.

The results demonstrated that the zone of bacterial inhibition by AFS prepared from marine sponge extract show maximum inhibition for gram positive B.Subtilis which may be concluded from the fact that the particles had the smallest diameter than those prepared from other methods, which in turn exhibited equal antimicrobial property. From the above results, we can conclude that AFS exhibits excellent antibacterial activity than the pure sponge extract. Hence, the as-synthesized AFS shows remarkable antimicrobial performances towards the clinical isolates.

\subsection{In vitro cytotoxicity studies}

Cytotoxic effect of marine sponge and AFS on HELA cells was evaluated using MTT assay. As shown in Fig. 11 marine sponge and AFS caused a dosage dependent inhibition of cell proliferation towards HELA cells. The cell viability was recorded as $94 \%$ and $85 \%$ in marine sponge at $20 \mu \mathrm{g} / \mathrm{ml}$ and $40 \mu \mathrm{g} / \mathrm{ml}$ concentrations and the maximum decrease in cell viability were measured as $45 \%$ at $140 \mu \mathrm{g} / \mathrm{ml}$ at $24 \mathrm{~h}$. Marine sponge show lesser toxic effect due to the biological origin. In contrast, AFS was recorded high cytotoxic at low concentration and the IC50 value was $94 \mu \mathrm{g} / \mathrm{ml}$. The maximum decrease of $24 \%$ cell viability was measured after treatment with $140 \mu \mathrm{g} / \mathrm{ml}$ of AFS. Combination of AFS and the presence of marine sponge components, the cytotoxic effects were increased at lower concentrations ${ }^{38}$.

\subsection{Morphological assessment}

As shown in Fig. 12, the untreated HELA cells maintained their original morphology and attached properly even when the incubation was $24 \mathrm{~h}$. In contrast, HELA cells lost their original shape at $24 \mathrm{~h}$ of $100 \mu \mathrm{g} / \mathrm{mL}$ marine sponge treatment and it has not shown maximum damage at $80 \mu \mathrm{g} / \mathrm{mL}$. The HELA cells had lost their elongated spindle-shape morphology when it was treated with AFS at low concentration $(80 \mu \mathrm{g} / \mathrm{mL})$. When the AFS treatment of $100 \mu \mathrm{g} / \mathrm{mL}$ concentration, suspension cells (dead cells) were identified and more suspension cells were observed at $120 \mu \mathrm{g} / \mathrm{mL}$. AFS were damage more cells in HELA cancer cells compare to marine sponge.

\subsection{Cellular uptake}

The AgNPs cancer cells uptake was observed by fluorescent microscopy (Fig. 5). Silver nanoparticle uptake was found to be more particles in HELA cells based on the concentration. In initial concentration of $1 \mu \mathrm{M}$ fluorescent intensity in the cancer cell was less over the time. AgNPs was penetrated into the cell via passive diffusion and $20 \mathrm{~nm}$ size nanoparticles can be easily internalized deeply into tumor cells. FITC-AgNPs showed aincreasing green fluorescent signal for $3 \mu \mathrm{M}$ and $4 \mu \mathrm{M}$ and nuclear region were consist of smaller particles. It suggests the concentration-dependent cellular uptake directly localize material to nucleus. 


\section{Conclusion}

In conclusion, this is the first one pot phyto-synthesis of AFS using the marine sponge Clathriafrondifera extract and as mentioned method is simple, rapid, stable and eco-friendly. The crystallinity and morphologies were confirmed by XRD, SEM, TEM and EDX analysis. The functional chemical groups involved during the synthesis which was identified through FTIR studies and further confirmed with GCMS data. The synthesized AFS showed an excellent antimicrobial efficacy towards the both gram positive and gram negative pathogens. AgNPs have higher cellular uptake, it induced a concentration-dependent cytotoxicity by increasing ROS level and damage the cells. In the recent progress and the on-going efforts in improving particle synthesis efficiency and exploring their biomedical applications, it is hopeful that the execution of the approach of ours on a large scale and their commercial applications in medicine and health care will be very much useful in the upcoming years. Hence, further rigorous studies are required to utilize these nanoparticles for their use in various formulations such as in bandages, ointments, gels, lotions and all other formulations in intradermal applications for problems arising from skin cancer or healing process of the epidermal layers of the body.

\section{References}

1. A. Shakeri and A. Sahebkar, Anti-Cancer Products from Marine Sponges: Progress and Promise, Recent Patents on Drug Delivery \& Formulation, 2015, 9(3), 1-2.

2. S. Ravichandran, K. Kathiresan and H. Balaram, Anti-malarials from marine sponges. Biotechnol Mol Biol Rev 2007; 2(2): 03.

3. L. Fieseler, M. Horn, M. Wagner and U. Hentschel, Discovery of the novel candidate phylum "Poribacteria" in marine sponges. Appl Environ Microbiol 2004; 70(6): 3724-32.

4. A. Mollica, M. Locatelli, A. Stefanucci and F. Pinnen, Synthesis and bioactivity of secondary metabolites from marine sponges containing dibrominated indolic systems, Molecules 2012, 17(5): 6083-99.

5. Y. Sumii, N. Kotoku, A. Fukuda, T. Kawachi, M. Arai and M. Kobayashi, Structure-activity relationship and in vivo antitumor evaluations of dictyoceratin-A and $-\mathrm{C}$, hypoxia-selective growth inhibitors from marine sponge, Marine Drugs, 2015, 13(12), 7419-7432.

6. D. T. A. Youssef, L. A. Shaala and K. Z. Alshali, "Bioactive hydantoin alkaloids from the Red Sea marine sponge Hemimycale arabica," Marine Drugs, 2015, 13(11), 6609-6619.

7. D. Inbakandan, R. Venkatesan and S. Ajmal Khan, Colloid. Surf. B: Biointerface.,2010, 81, 634-639.

8. R. Hamed, M. H. Givianrad and A. M. Moradi, Orient. J. Chem., 2015, 31, 1961-1967.

9. M. R. Hamed, M. H. Givianrad and A. M. Moradi, Ind. J. Geo. Marine. Sci., 2017, 46, 125-130.

10. Y. N. Shkryl, G. N. Veremeichik, D. G. Kamenev, T. Y. Gorpenchenko, Y. A. Yugay, D. V. Mashtalyar, A. V. Nepomnyaschiy, T. V. Avramenko, A. A. Karabtsov, V. V. Ivanov, V. P. Bulgakov, S. V. Gnedenkov, Y. N. Kulchin and Y. N. Zhuravlev, Nanomed.Biotechnol., 2017, 46, 1646-1658.

11. G. Radhika, R. Venkatesan and S. Kathiroli, Ind. J. Marine. Sci., 2007, 36, 235-238. 
12. K. Saravanakumar, B. Ramkumar andV. Muthuraj, Int. J. Res. Phar. Chem., 2016, 6, 458-464.

13. S. H. Hassanpour and M. Dehghani, Review of cancer from perspective of molecular, Journal of Cancer Research and Practice, 2017, 4, 127-129

14. A. G. Waks and E. P. Winer, Breast Cancer Treatment, JAMA, 2019, 321(3), 288-300.

15. A. F. Santos, D. R. Q. Almeida, L. F. Terra, M. S. Baptista and L. Labriola, Photodynamic therapy in cancer treatment - an update review, J Cancer Metastasis Treat, 2019, 5(25) 1-20.

16. H. Yang, R. M. Villani, H. Wang, M. J. Simpson, M. S. Roberts, M. Tang and X. Liang, The role of cellular reactive oxygen species in cancer chemotherapy, Journal of Experimental \& Clinical Cancer Research, 2018, 37(266),

17. C. Thallinger, T. Fureder, M. Preusser, G. Heller, L. Mullauer, C. Holler, H. Prosch, N. Frank, R. Swierzewski, W. Berger, U. Jager and C. Zielinski, Review of cancer treatment with immune checkpoint inhibitors, wiener klinische wochenschrift, 2018, 130, 85-91.

18. R. Misra, S. Acharya, S. K. Sahoo, Cancer nanotechnology: application of nanotechnology in cancer therapy, Drug Discovery Today, 2010, 19-20, 842-850.

19. J. Shi, P. W. Kantoff, R. Wooster and O. C. Farokhzad, Cancer nanomedicine: progress, challenges and opportunities, Nature reviews: cancer, 2017, 17, 21-37.

20. V. P. Chauhan and R. K. Jain, Strategies for advancing cancer nanomedicine, Nature Materials, 2013 , $12,958-962$.

21. A. Wicki, D. Witzigmann, V. Balasubramanian, J. Huwyler, Nanomedicine in cancer therapy: Challenges, opportunities, and clinical applications, Journal of Controlled Release, 2015, 200, 138157.

22. P. Kumar, M. Govindaraju, S. Senthamilselvi and K. Premkumar, Colloid. Surf. B. Biointerface., 2013, 103, 658- 66.

23. S. Y. Seo, G. H. Lee, S. G. Lee, S. Y. Jung, J. O. Lim and J. H. Choi, Carbohydr. Polym., 2012, 90, 109115.

24. A. Aravinthan, M. Govarthanan, K. Selvam, L. Praburaman, T. Selvankumar, R. Balamurugan, S. Kamala-Kannan and J. Kim, Int. J. Nanomed., 2015, 10, 1977-1983.

25. N. Vigneshwaran, R. P. Nachane, R. H. Balasubramanya and P. V. Varadarajan, Carbohyd. Res., 2006, 341, 2012-2018.

26. S. Dinesh, S. Karthikeyan and P. Arumugam, Elixir Optical Mater., 2012, 44, 7364-7366.

27. P. Banerjee, M. Satapathy, A. Mukhopahayay and P. Das, Bioresources and Bioprocessing, 2014, 1, 110.

28. S. Singh, J. P. Saikia and A. K. Buragohain, Colloid. Surf. B: Biointerface.,2013, 102, 83-85.

29. N. Asmathunisha and K. Kathiresan, Colloid. Surf. B,2013, 103, 283-287.

30. N. Vigneshwaranm, N. M. Ashtaputre, P. V. Varadarajan, R. P. Nachane, K. M. Paralikar and R. H. Balasubramanya, Mater. Lett., 2007, 61, 1413-1418. 
31. N. S. Shaligram, M. Blue, R. Bhambure, R. S. Singhal, S. K. Singh, G. Szakacs and A. Pandey, Proc. Biochem., 2009, 44, 939-943.

32. M. Vivek, P. S. Kumar, S. Steffi, S. Sudha, Avicenna J. Med. Biotechnol., 2011, 3, 143-148

33. M. H. Givianrad, T. Sadeghi, K. Larijani and S. E. Hosseini, J. Food Tech. Nutr., 2011, 30, 38-44.

34. R. Singh, S. K. Sahu and M. Thangaraj, J. Nanoparticle., 2014, 718240, 1-7.

35. N. Asmathunisha and K. Kathiresan, Colloid. Surf. B: Biointerface.,2013, 103, 283-287.

36. K. Govindaraju, V. Kiruthiga, G. V. Kumar and G. Singaravelu, J. Nanosci. Nanotechnol., 2009, 9, 54975501.

37. D. Inbakandan, G. Sivaleela, D. Magesh Peter, R. Kiurbagaran, R. Venkatesan and S. Ajmal Khan, Mater. Lett.,2012, 87, 66-68.

38. M. Jeyaraj, M. Rajesh, R. Arun, D. Mubarak Ali, G. Sathishkumar, G. Sivanandhan, G. Kapil Dev, M. Manickavasagam, K. Premkumar, N. Thajuddin and A. Ganapathi, Colloids Surf. B., 2013, 102, 708717.

\section{Tables}

Table 1. Collective data for the synthesis of AgNPs

\begin{tabular}{|lllll|}
\hline Extract & Sponge $\mathbf{( 5} \mathbf{g})$ & $\begin{array}{l}\text { Solvent } \\
(\mathbf{5 0} \mathbf{~} \mathbf{L})\end{array}$ & Extraction method & Time \\
\hline I & shadow dried & water & Boiling & $30 \mathrm{~min}$ \\
\hline II & Dried and manually crushed & $1: 10(\mathrm{MeOH}:$ water $)$ & Soaking & $24 \mathrm{hr}$ \\
\hline
\end{tabular}

\section{Figures}




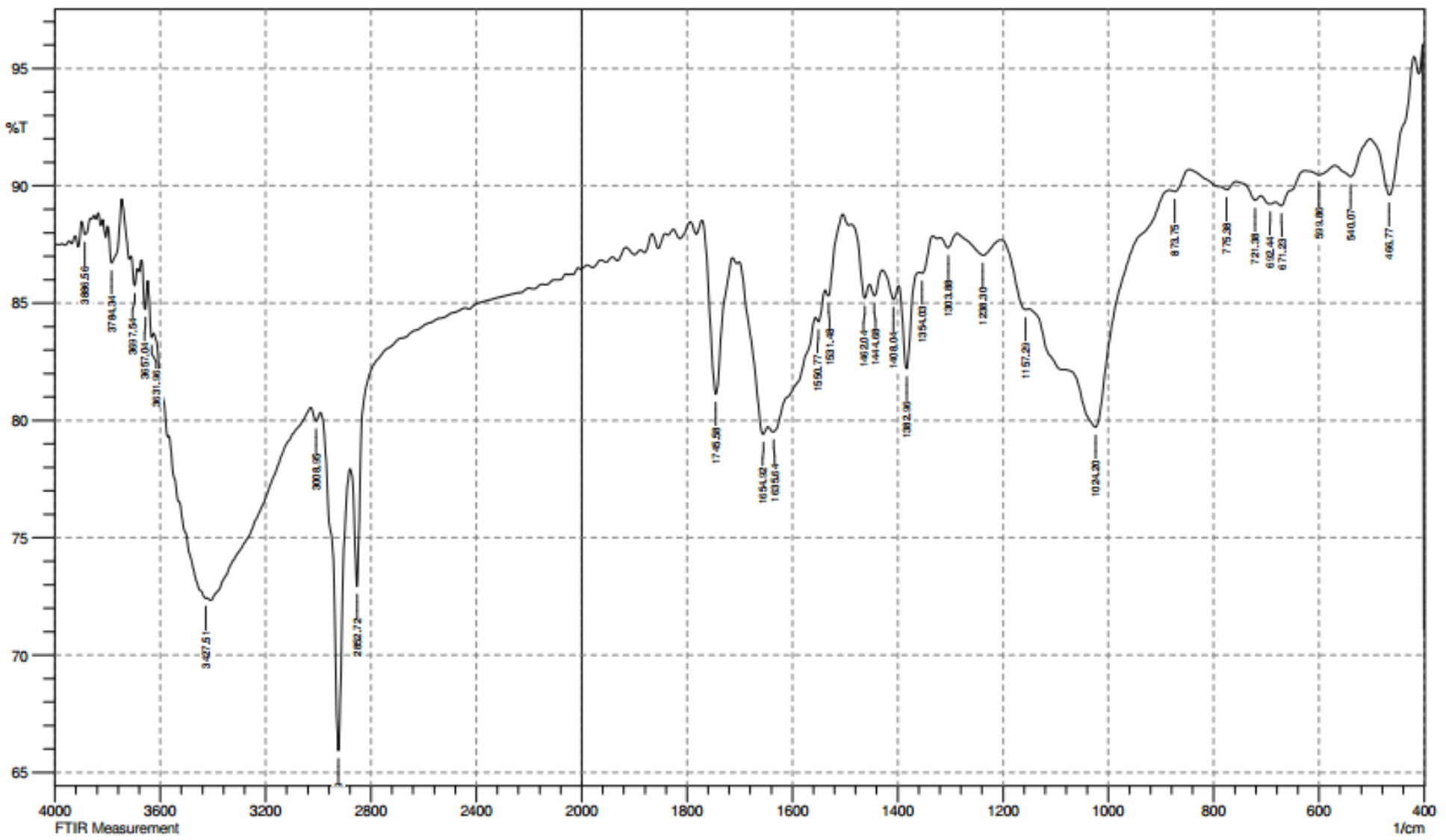

Figure 1

FTIR spectrum of crushed and sieved fine powder of Clathria frondifera marine sponge 


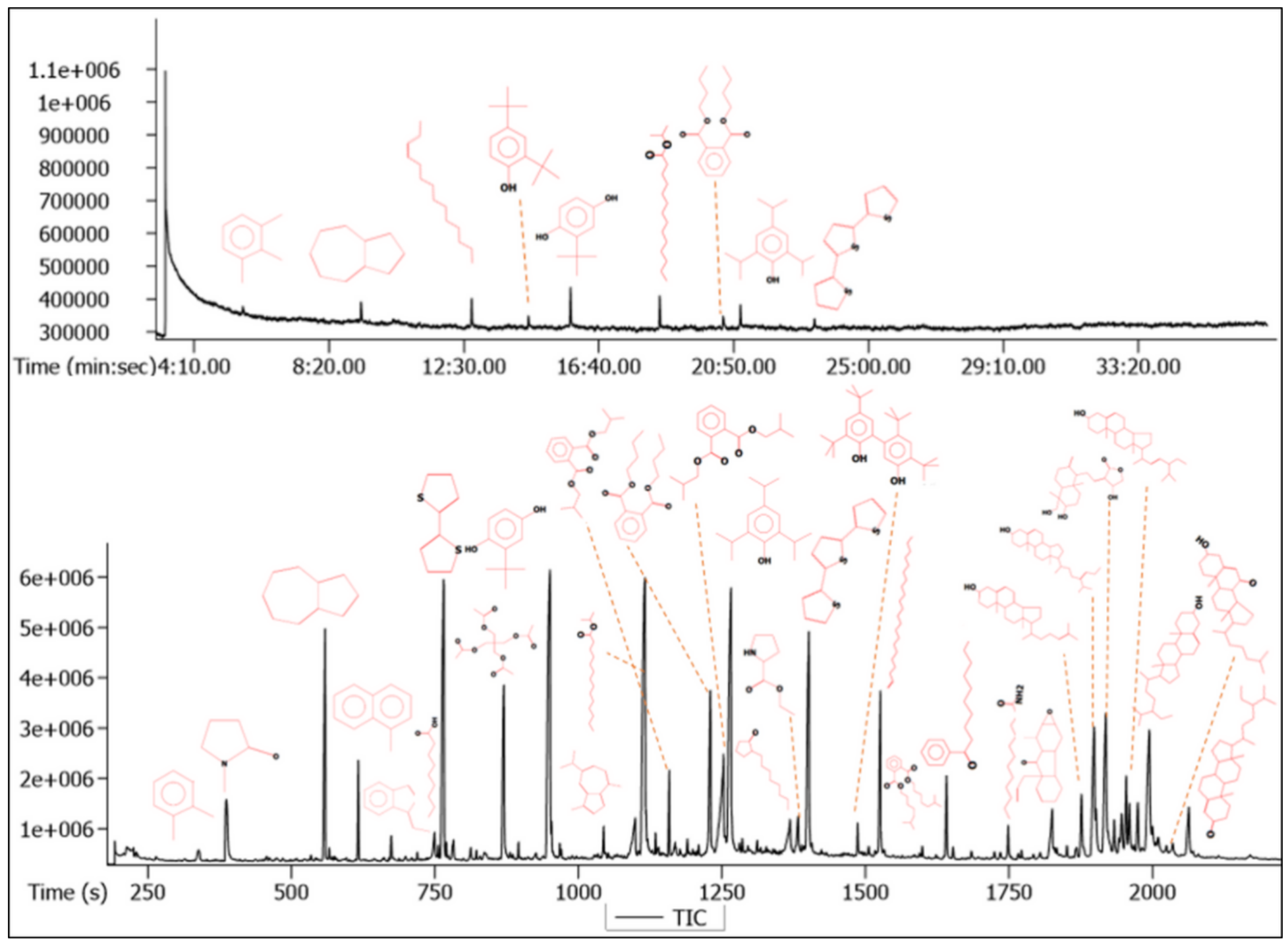

Figure 2

Gas chromatogram along with their corresponding molecular structures of extracts (I -up and II - down) of marine sponge Clathria frondifera 


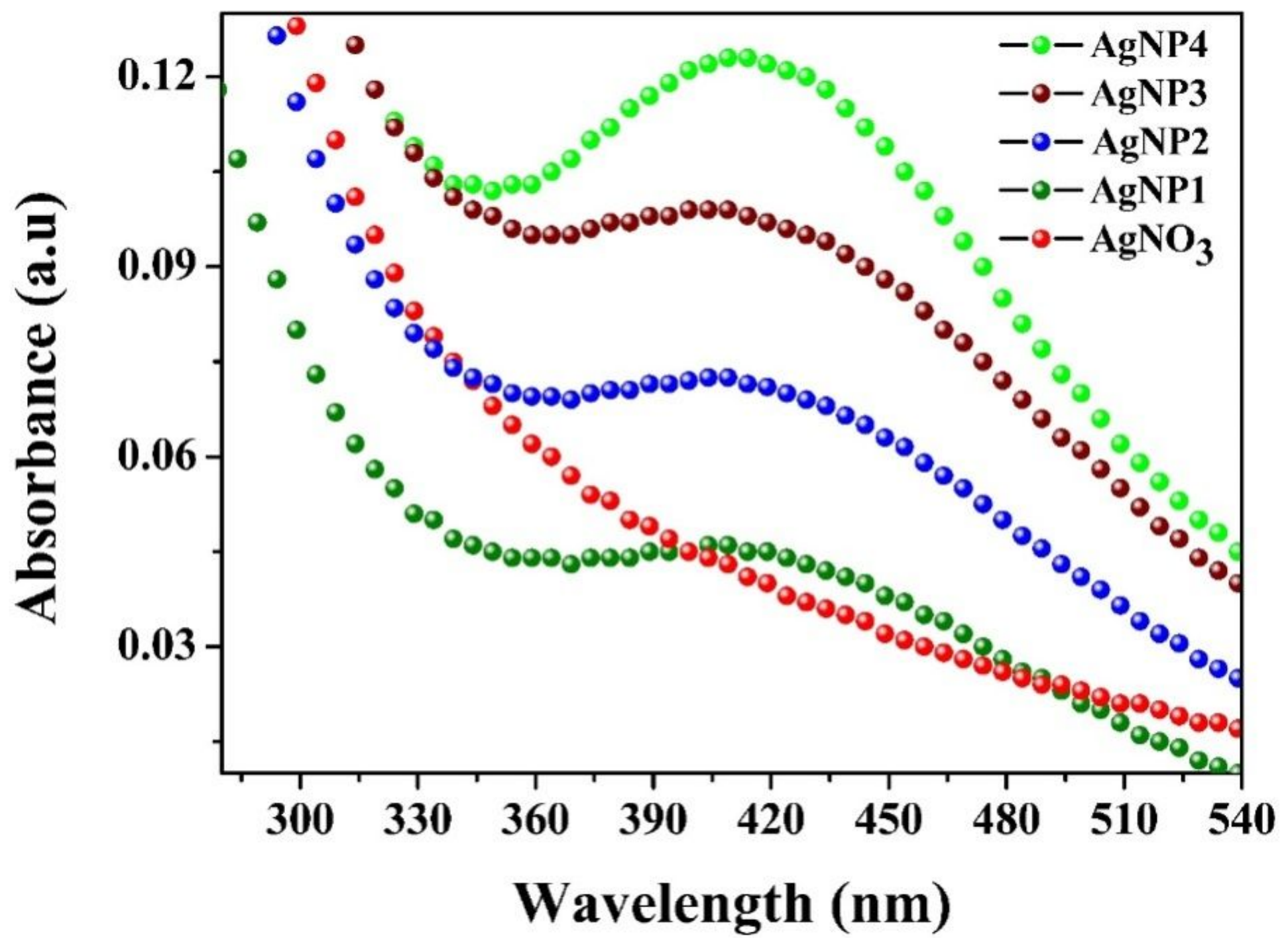

Figure 3

UV-Visible absorbance spectra of solutions of (1:3) AgNP4 during the reaction 


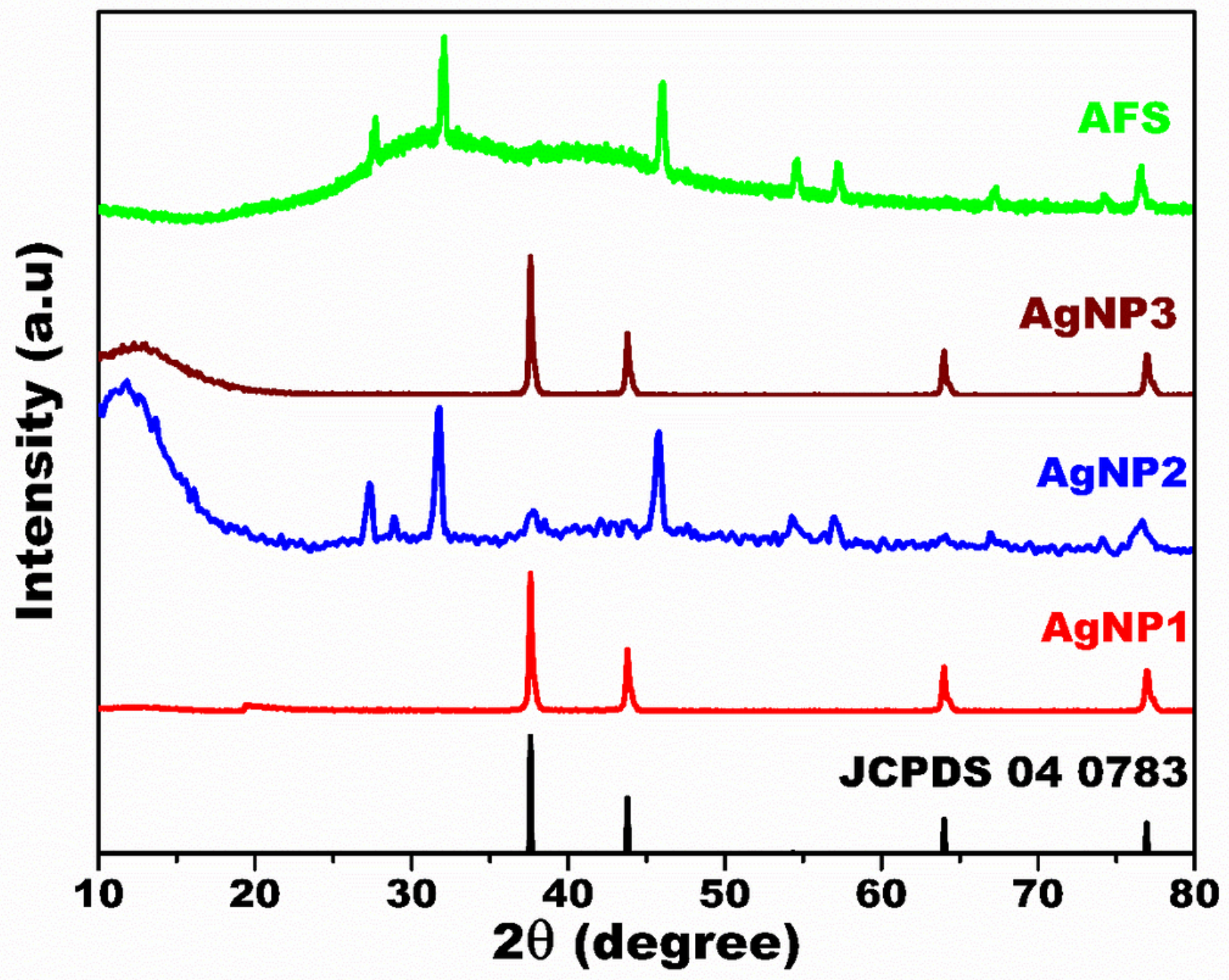

Figure 4

Powder XRD pattern of Ag nanoparticles and 1:3 Ag fortified sponge microspheres 


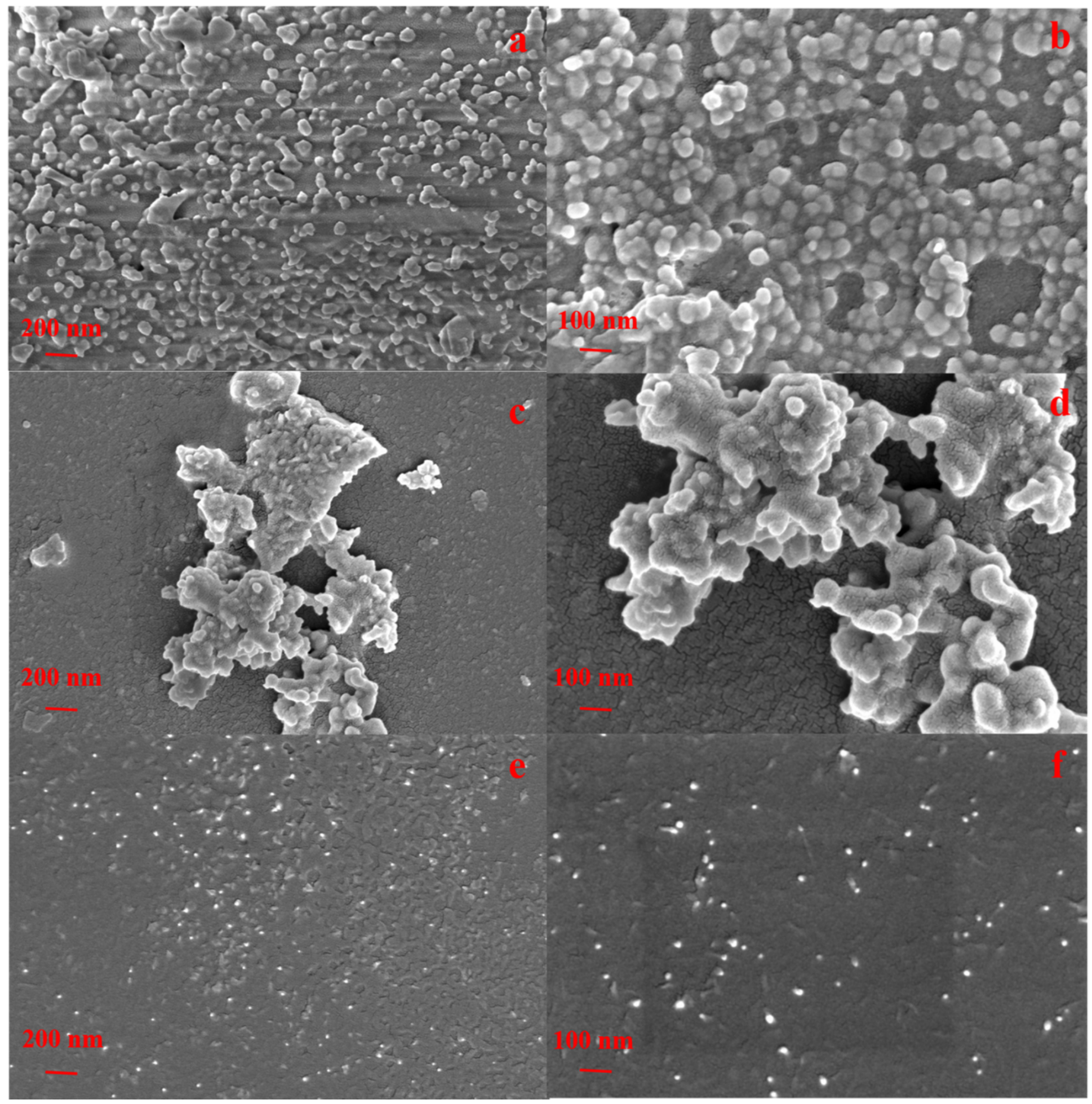

\section{Figure 5}

SEM images of AgNP1 (a,b), AgNP2 (c,d), and AgNP3 (e,f) 


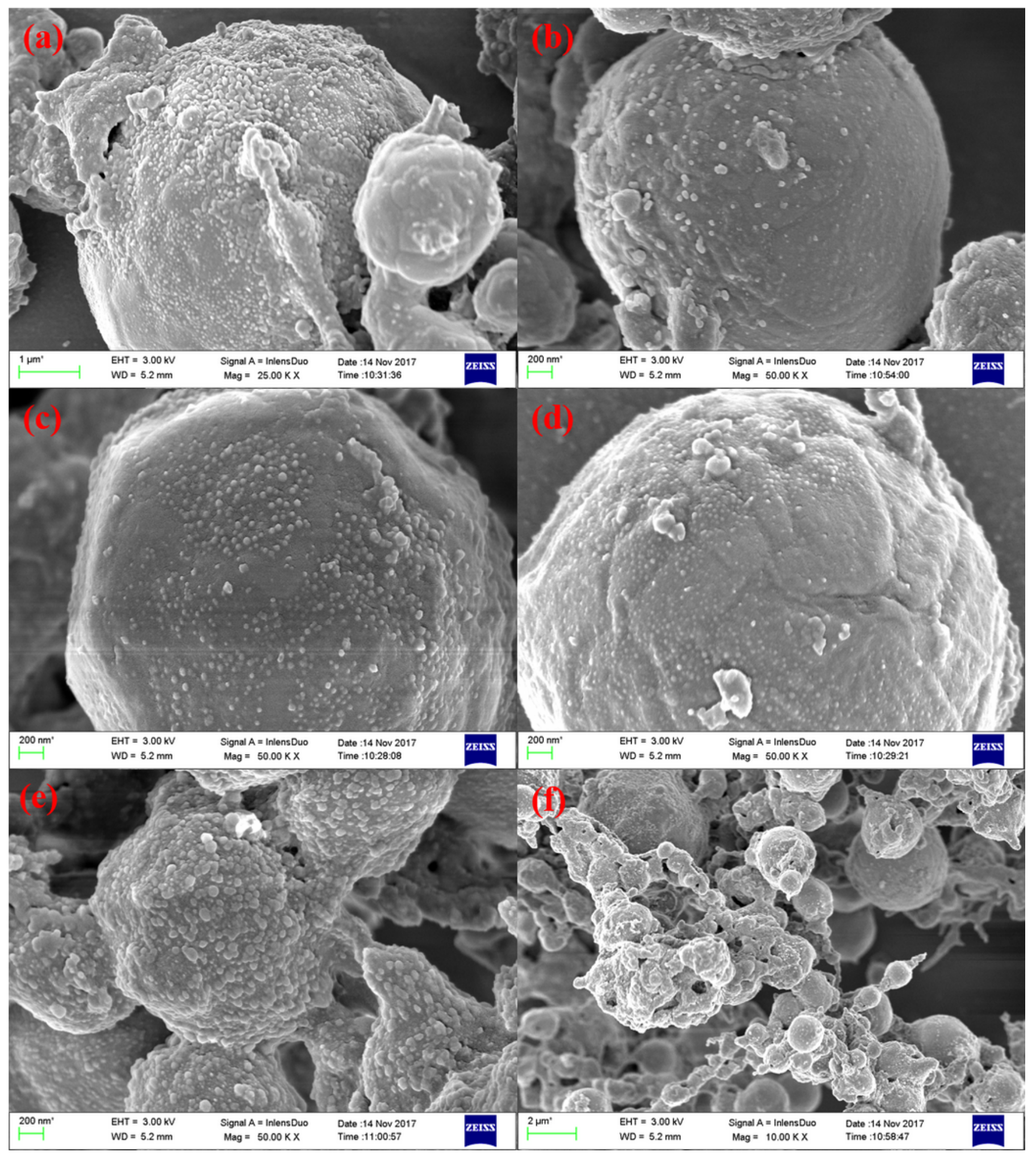

Figure 6

SEM images of silver fortified marine sponge microspheres (AgNP4) synthesized using various stoichiometric ratios of AgNO3 and extract II solutions (a) 1:1, (b)1:2 (c, d) 1:3 (e) 2:1 (f) 3:1 


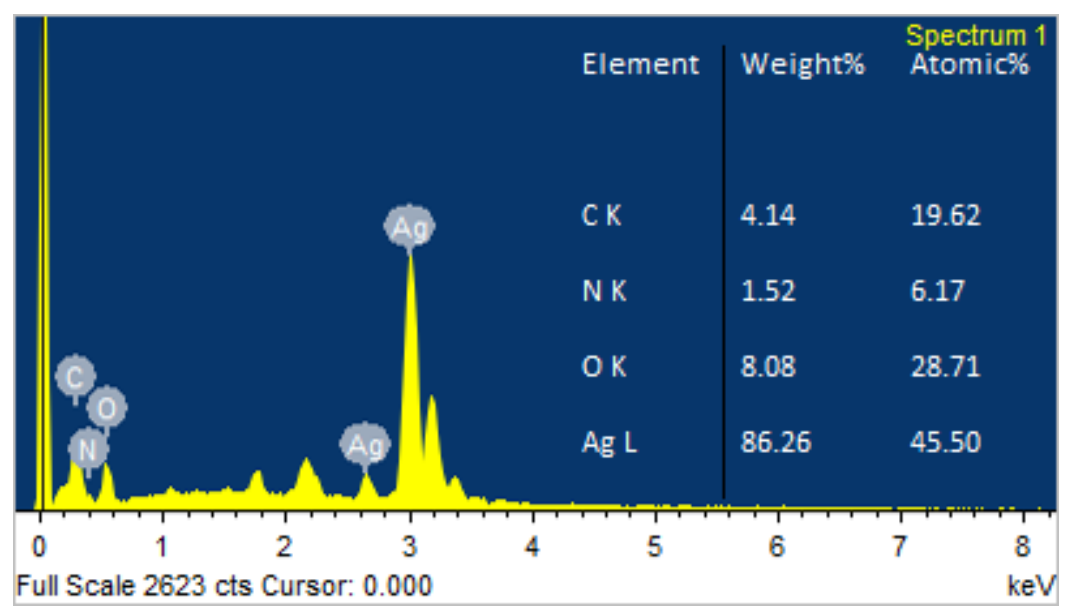

Figure 7

EDAX spectrum of 1:3 Ag fortified marine sponge microspheres of marine sponge Clathria frondifera

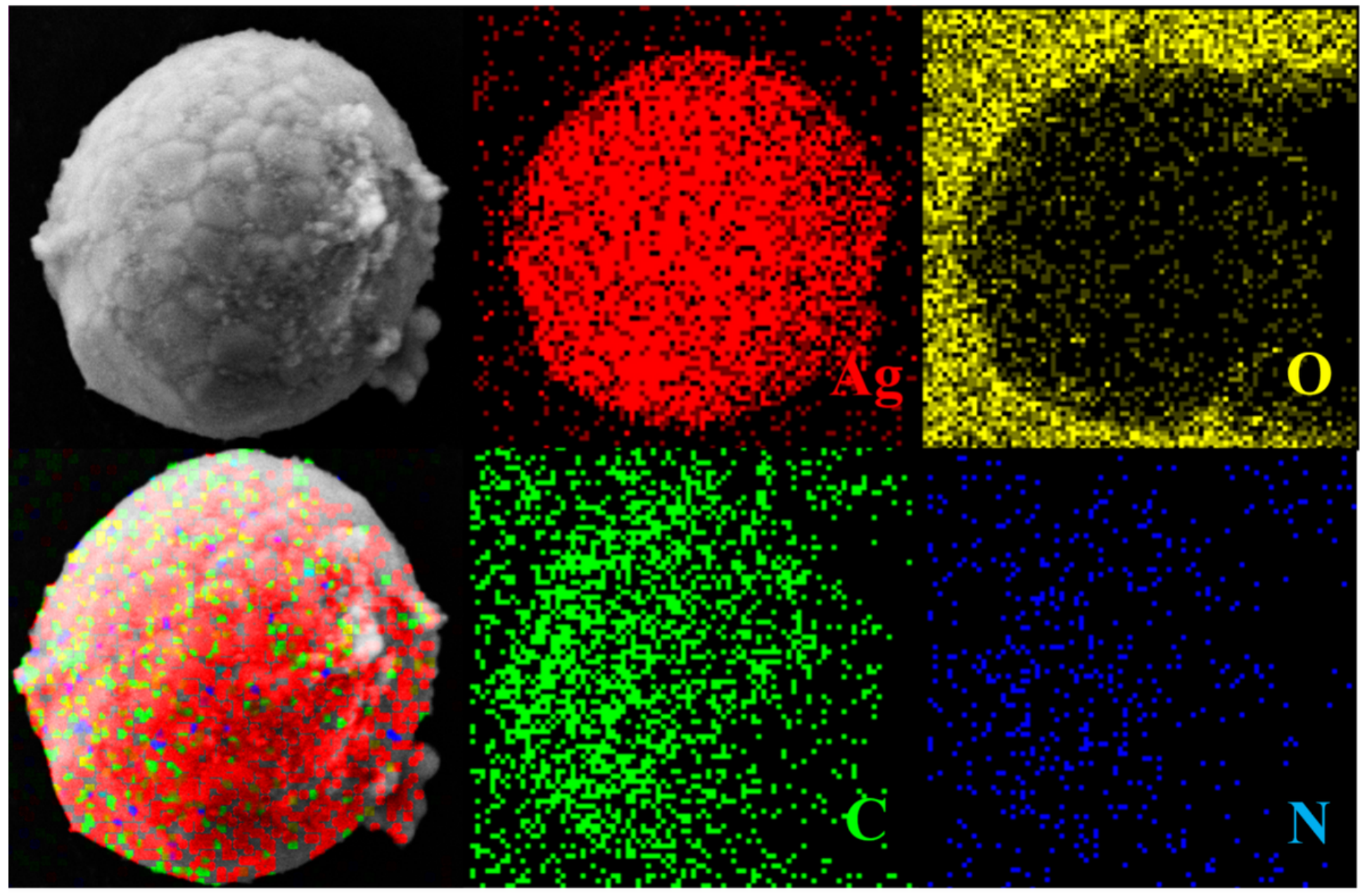

Figure 8

Elemental mapping images of 1:3 Ag fortified marine sponge microspheres (silver - red, oxygen - yellow, carbon - green, nitrogen - blue) 


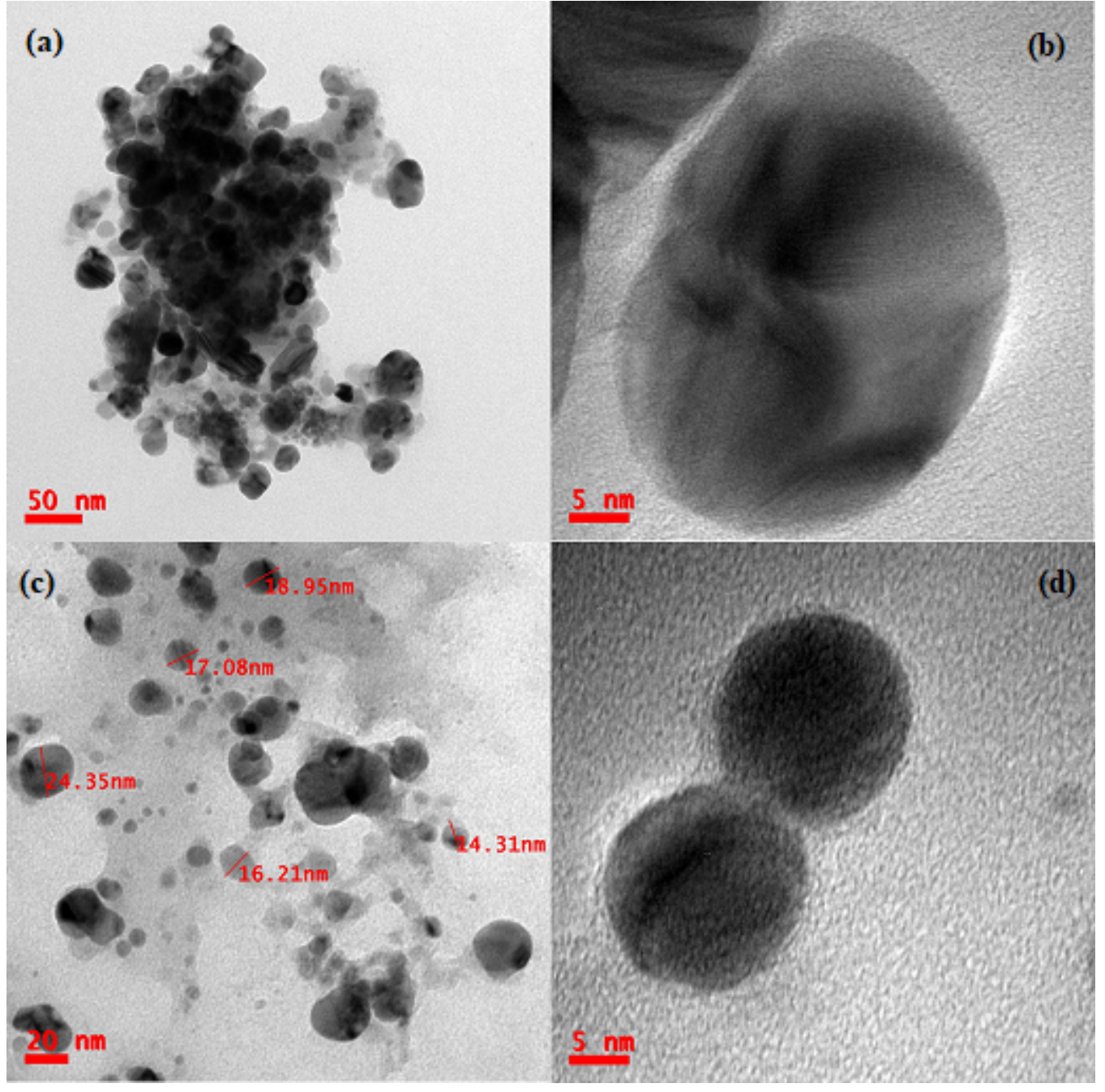

Figure 9

TEM images of 3:1 AgNP4 nanoparticles $(a, b)$ and 1:3 Ag fortified sponge microspheres (c, d)

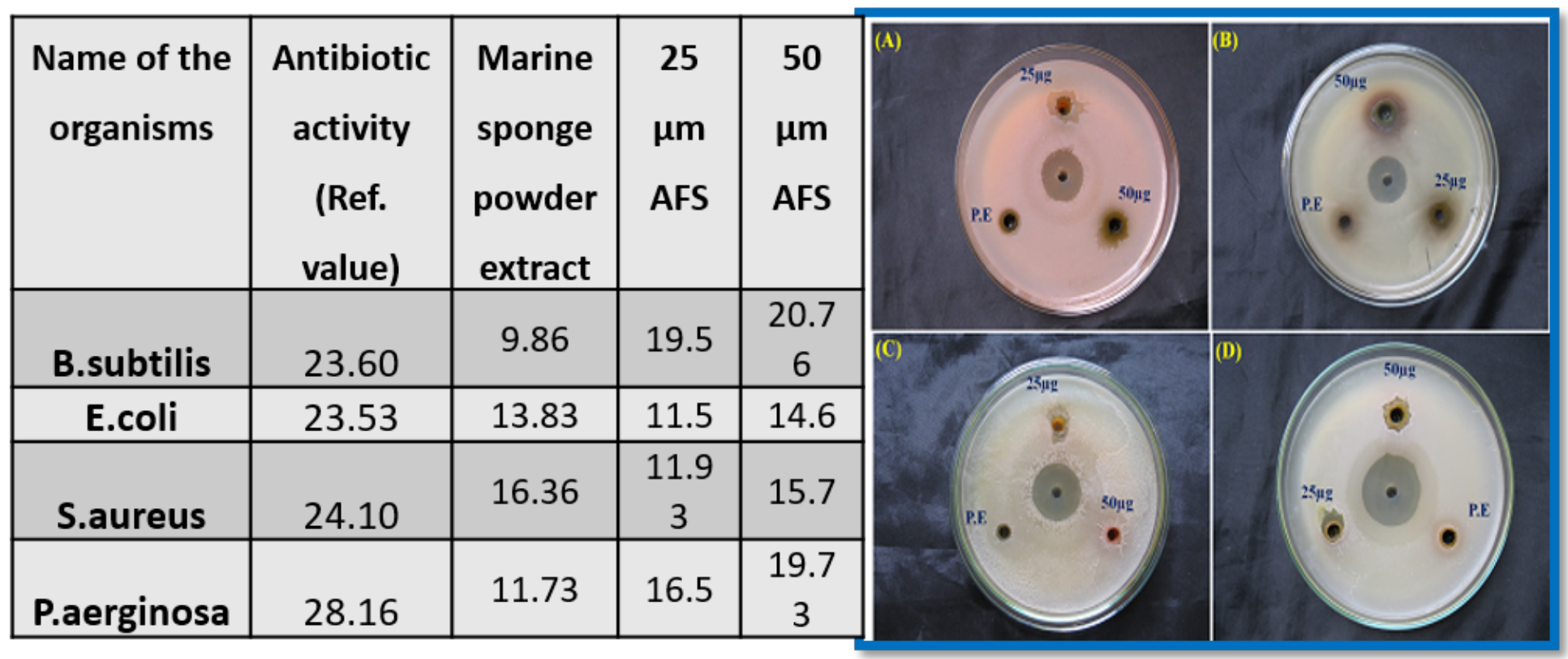

Figure 10 
Antimicrobial activity of AFS against (A)Escherichia coli, (B) Bacillus subtilis, (C) Staphylococcus aureus and (D) Pseudomonas aeruginosa clinical isolates

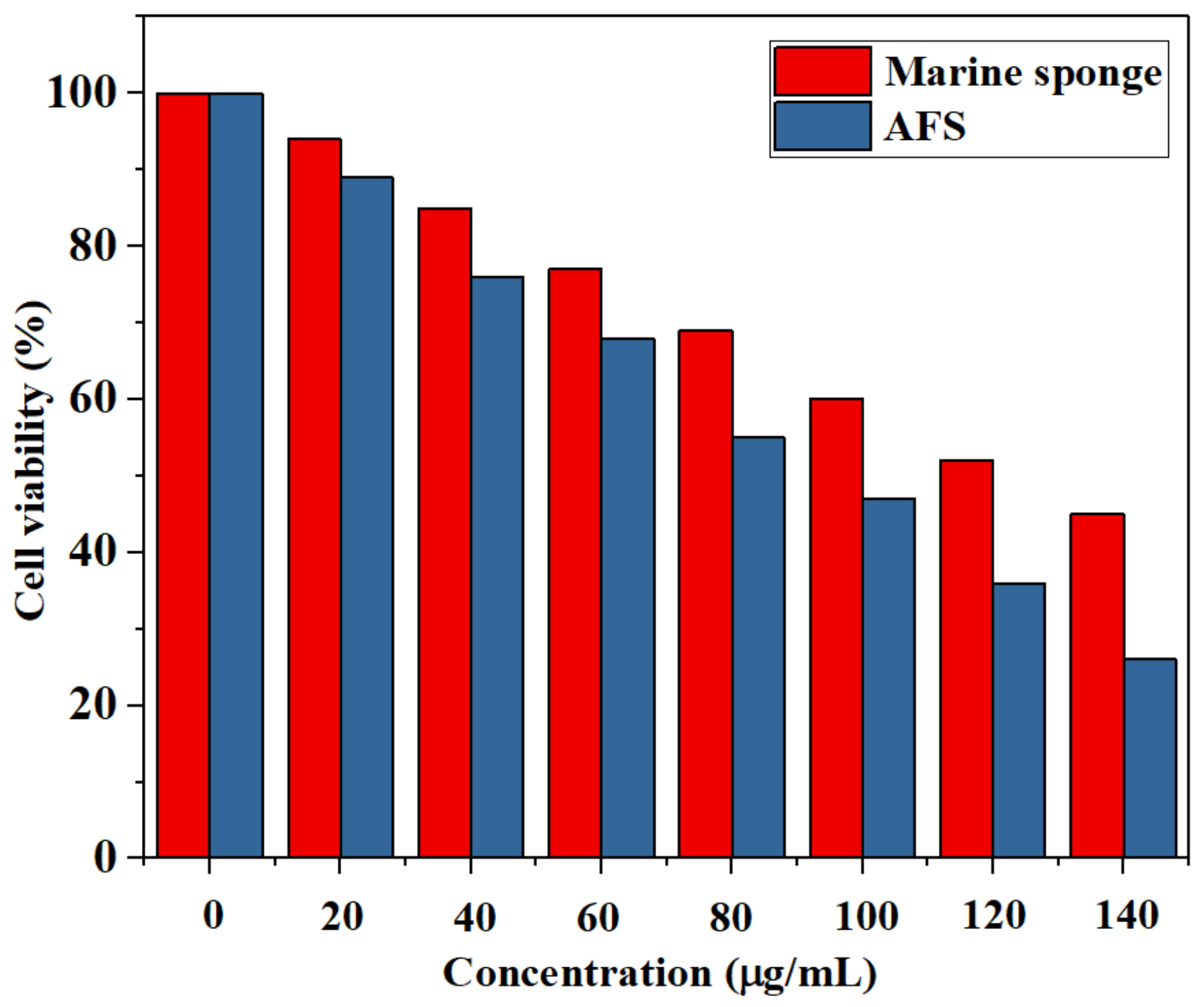

Figure 11

Cell viability studies after exposure of marine sponge and AFS to HELA cells for $24 \mathrm{~h}$. 


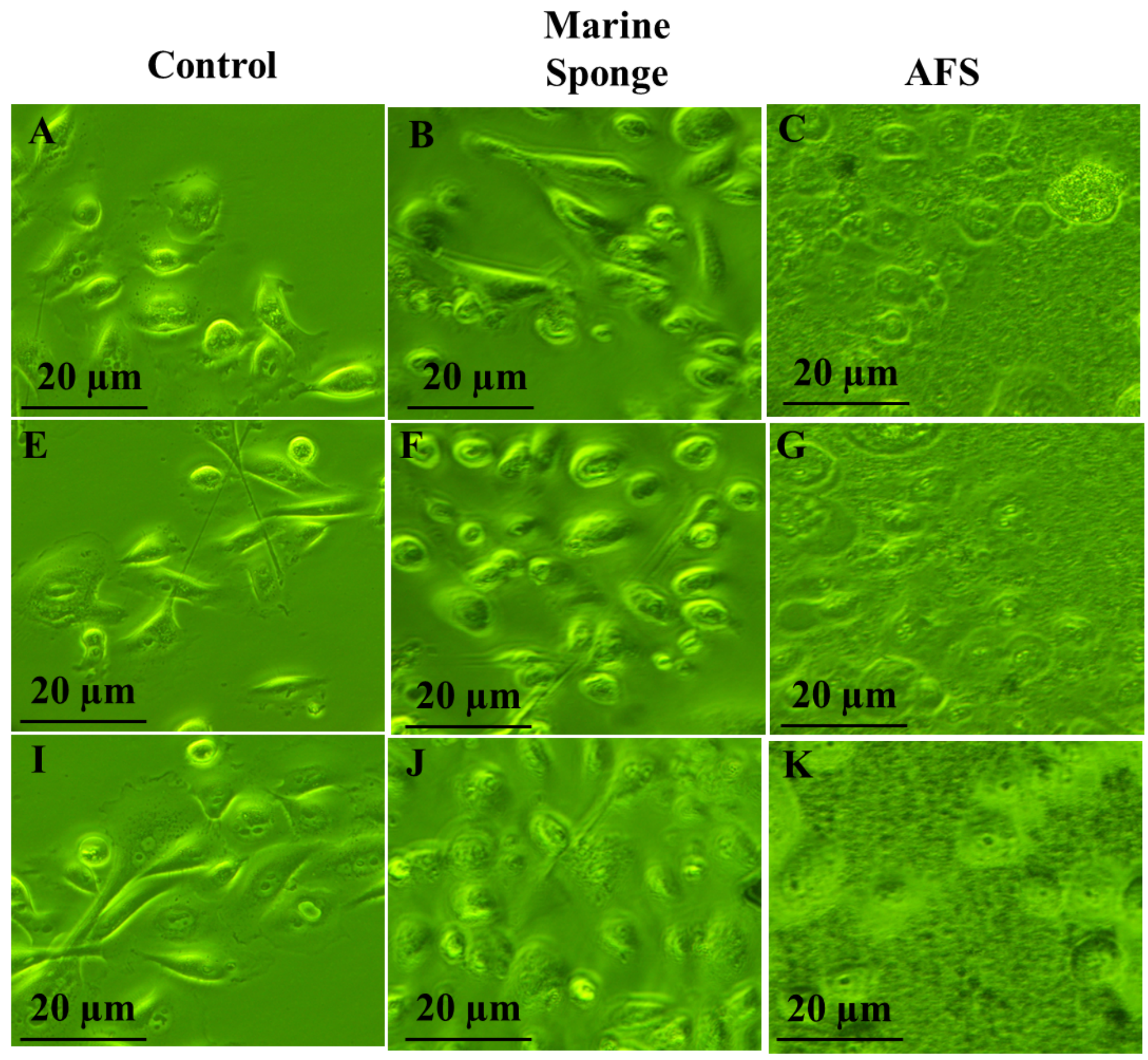

Figure 12

Morphology analysis after exposure of marine sponge $(80,100,120 \mu \mathrm{g} / \mathrm{mL})$, AFS $(80,100,120 \mu \mathrm{g} / \mathrm{mL})$ to HELA cells for $24 \mathrm{~h}$. 


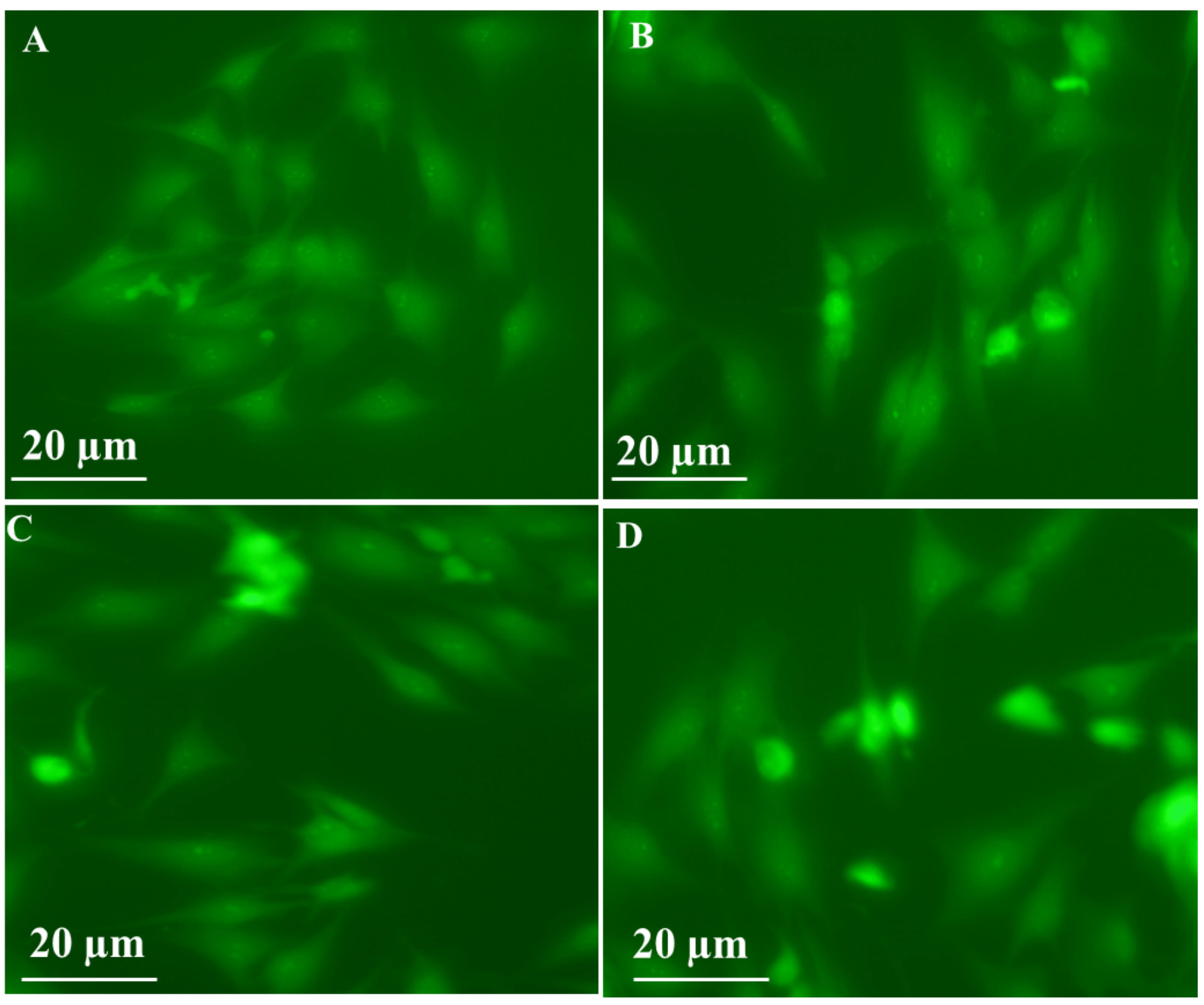

Figure 13

Cellular uptake study of FITC-AgNPs(A) $1 \mu \mathrm{M}$ (B) $2 \mu \mathrm{M}$ (C) $3 \mu \mathrm{M}$ (D) $4 \mu \mathrm{M}$

\section{Supplementary Files}

This is a list of supplementary files associated with this preprint. Click to download.

- Tableofcontent.docx 